\title{
Consequences of cruise line involvement: a comparison of first-time and repeat passengers
}

\begin{abstract}
Purpose: This study aims to test the relationships among involvement, perceived price, perceived quality, affective satisfaction, perceived value, attitudinal loyalty and behavioral loyalty in the cruise line industry. In addition, this study attempted to identify whether the differences in these variables exist across first-time and repeat cruise customers. Design/methodology/approach: The web-based survey was used. A total of 403 complete responses were used for data analysis. Anderson and Gerbing's (1988) two-step approach was used to achieve study objectives. Findings: The t-test analyses demonstrated that repeat cruise customers expressed significantly lower perceived price and higher affective satisfaction, perceived value and behavioral loyalty than first-time cruise travelers. The structural equation modeling results revealed that involvement has an important role in loyalty generation process. However, the structural model did not significantly differ across first-time and repeat customers. Practical implications: Overall, the results indicated the critical needs to develop individuals' interest in cruise vacation with a particular cruise line. Cruise line operators who undertake promotion efforts that enhance people involvement with their cruise line should result in greater likelihood of choosing the same cruise line in the future. Originality/value: With a lack of research about cruise line involvement and loyalty, this research contributes to theoretical understanding of intricate attitudinal and behavioral loyalty generation process across first-time and repeat cruise passengers.
\end{abstract}

Keyword: Involvement; Perceived price; Customer loyalty; Affective satisfaction; Cruise line; Previous experience 